\title{
Bidirectional selection for olfactory response to acetaldehyde and ethanol in Drosophila melanogaster
}

\author{
A.A. HOFFMANN \\ Department of Genetics and Human Variation, La Trobe University \\ Bundoora, Victoria, Australia, 3083
}

\begin{abstract}
Summary
Drosophila melanogaster adults were successfully selected for increased and decreased olfactory response to different concentrations of acetaldehyde and ethanol, using a choice type olfactometer. The response to selection was not concentration specific.

Lines were also tested with n-propanol, n-butanol, acetic acid, propionic acid, benzaldehyde, methyl acetate, ethyl acetate and 3-hydroxybutan-2-one. The behaviour of the lines was similar for most of these chemicals, indicating an odorant specific response to selection. However, ethanol selected lines differed in their response to n-propanol and possibly n-butanol, suggesting a role for the alcohol group in determining the specificity of genetic variation in olfactory response.

Utilization of acetic acid, ethanol and acetaldehyde as resources by the selected lines was tested using adult longevity. The only significant result was that lines selected for increased attraction to ethanol utilised 9 p. 100 and 12 p. 100 ethanol more than lines selected for decreased attraction.

Gene frequencies were monitored at 3 enzyme loci - alcohol dehydrogenase, triose phosphate isomerase, $\alpha$-glycerophosphate dehydrogenase - associated with the metabolism of ethanol and acetaldehyde. There were no changes associated with the response to selection, and the ADH-F allele increased in both selected and unselected lines.
\end{abstract}

Key words : Olfactory response, Drosophila melanogaster, behaviour genetic variation, resource utilization.

\section{Résumé \\ Sélection bidirectionnelle de la réponse olfactive à l'acétaldéhyde et à l'éthanol chez $\mathrm{D}$. melanogaster}

Des adultes de Drosophila melanogaster ont été sélectionnés avec succès pour un accroissement ou une diminution de la réponse olfactive à différentes concentrations d'acétaldéhyde ou d'éthanol. La sélection a été faite dans un olfactomètre à choix et la réponse obtenue n'est pas spécifique de la concentration.

Les lignées ont été aussi testées avec le n-propanol, n-butanol, l'acide acétique, l'acide proprionique, le benzaldéhyde, l'acétate de méthyle, l'acétate d'éthyle et le 3-hydroxy-2butanone. Le comportement des lignées a été semblable pour la plupart de ces produits, montrant que la sélection concerne la capacité de réponse à une odeur. Cependant, les 
lignées sélectionnées pour l'éthanol ont différé dans leur réponse au n-propanol et peut-être au n-butanol, suggérant que le groupe alcool a pu jouer un rôle dans la spécificité de la variation génétique de la réponse olfactive.

L'utilisation de l'acide acétique, de l'éthanol et de l'acétaldéhyde comme ressource a été testée chez les lignées sélectionnées grâce à une étude de la longévité. Le seul résultat significatif a été que les lignées sélectionnées pour une plus forte attraction par l'éthanol utilisaient, mieux que les lignées sélectionnées pour une attraction décroissante, des concentrations d'alcool de 9 et 12 p. 100.

Les fréquences géniques ont été étudiées à 3 locus enzymatiques - la déshydrogénase alcoolique, la triose phosphate isomérase et l'a-glycérophosphate déshydrogénase - qui sont associés au métabolisme de l'éthanol et de l'acétaldéhyde : aucune modification associée à la sélection n'a été obtenue. L'allèle $A d h^{\mathrm{F}}$ a augmenté de fréquence à la fois dans les lignées sélectionnées et non sélectionnées.

Mots clés : Réponse olfactive, Drosophila melanogaster, variation génétique du comportement, utilisation des ressources.

\section{Introduction}

Olfaction is important in both long and short distance location of food by Drosophila (BARRow, 1907 ; Kellogg et al., 1962 ; Kennedy, 1977 a). Fuyama (1976) has described olfactory response variation among geographic strains of $D$. melanogaster for ethanol, ethyl acetate, n-butyraldehyde, and lactic acid, suggesting genetic variation in olfactory response in natural populations. Further genetic studies by FuYAma (1978) using chromosome II lines derived from a natural population indicated associations among the odorants tested. Variability among the lines was specific to esters and ketones, while the responses of the lines to these odorants were negatively correlated with their response to lactic acid.

Such odorant specific genetic variation in olfaction may be important in differential habitat utilization. One group of chemicals which has been studied from this perspective is ethanol and products associated with its metabolism. These fermentation products are present at high concentrations in Drosophila food resources (McKechNiE \& Morgan, 1982 ; MCKenzIE \& MCKechnie, 1979) and are attractive to Drosophila adults (HutNer et al., 1937 ; WEST, 1961). Ethanol, acetaldehyde and acetic acid are also used as resources in laboratory experiments (PARSONS \& SPENCE, 1981; Moxon et al., 1982).

Studies with Drosophila at the interspecific level have often indicated a direct relationship between the utilization of these chemicals and an elicited behavioural response. Examples are the oviposition behaviours of $D$. simulans and $D$. melanogaster on ethanol containing medium (McKenzie \& Parsons, 1972) and the larval attraction behaviours of these two species and D. immigrans to ethanol and acetic acid (PARsons \& Spence, 1981). At the intraspecific level, Gelfand \& McDonal.D (1980) and CAVENER (1979) have suggested a relationship between the alcohol dehydrogenase (ADH) allozymes involved in the utilization of ethanol and larval responses to this chemical. Studies with ADH null strains also indicate an association between ADH activity and both larval response to ethanol (PARSONS \& SPENCE, 1981) and oviposition on ethanol containing medium (Hougouto et al., 1982).

In this paper, I describe the response of a genetically heterogeneous $D$. melanogaster population to selection for increased and decreased attractiveness to ethanol and 
the metabolically related acetaldehyde. This experiment was carried out to determine whether odorant specific olfactory genetic variation to these common fermentation products exists, and whether an alteration of olfactory response is accompanied by a correlated response in the utilization of these chemicals as resources. The specificity of the selection response was determined by comparing the behaviour of the selected lines with other naturally occuring chemicals. Resource utilization was studied by measuring adult longevity in the presence of these chemicals. Gene frequencies were also monitored at three enzyme loci - triose phosphate isomerase (TPI), $\alpha$-glycerophosphate dehydrogenase (GPDH) and ADH - involved in the metabolism of these chemicals. ADH and GPDH cooperate metabolically in breaking down ingested alcohol and the subsequent synthesis of triglycerides/phosphatidic acids. Dihydroxyacetone phosphate is the common substrate for TPI and GPDH, occupying a central position in the distribution of triosephosphates for glycolysis and triglyceride/phosphatidic acid synthesis (SACKTOR, 1974).

\section{Materials and methods}

\section{A. Stocks}

Flies were obtained from a recently established population cage initiated by 50 females caught at an orchard site near Melbourne, Victoria. All stocks were maintained at $25^{\circ} \mathrm{C}$ on sugar-agar-dead yeast medium.

\section{B. Olfactometry}

A simple olfactometer was constructed (fig. 1), based on a design by Fuyama (1976). In the present, apparatus air was passed into trap tubes through glass cylinders rather than disposable needles, and rubber stoppers covered with replacable plastic were used instead of silicone stoppers. Laboratory air was passed through silica gel, charcoal and distilled water before being supplied to each trap tube at a rate of $7.5 \pm 1 \mathrm{ml} / \mathrm{min}$. All experimental runs were carried out in darkness at $25^{\circ} \mathrm{C}$.

Flies were observed under red light and appeared to respond mainly by walking upwind. Hence this olfactometer probably measures mostly mechanical anemotactic reponses (see KENNEDY, 1977 a). Wind shear forces in the choice area may also be important in such apparatuses (KENNEDY, $1977 \mathrm{~b}$ ) although little response occured in the absence of an airflow.

Flies used in experiments were collected when 0 to 2 days old and aged in vials for 20-25 hours at $20^{\circ} \mathrm{C}$. They were then sexed using an aspirator and placed into empty vials, 30 flies per vial, where they were starved at $20^{\circ} \mathrm{C}$ under high humidity (80-90 p. 100). Preliminary experiments had indicated an association between starvation time and olfactory response, with females attaining a maximum response after a longer starvation period than males. Hence females were starved for longer (30-39 hours) than males (25-32 hours), with both periods corresponding to a mortality of 5-15 p. 100 . Eighty five flies were used for each experimental run, which lasted 20 minutes. Other details are similar to those described by FuYama (1976). 


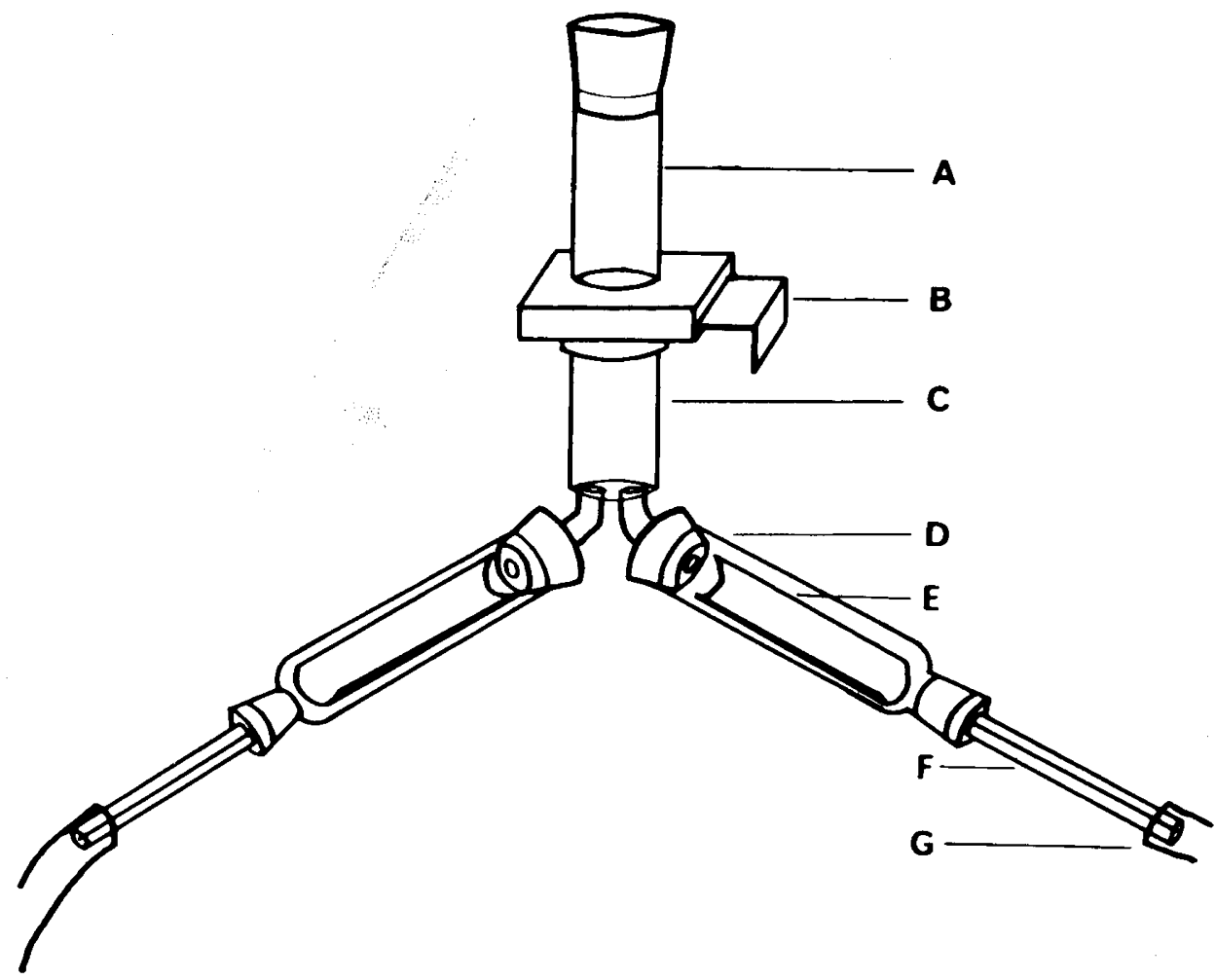

FIG. 1

The olfactometer.

Schéma de l'olfactomètre
A : Starting tube - Tube de départ.
B : Shutter - Volet.
C : Choice tube - Tube de choix.
D : Trap tube - Tube de capture.
E : Filter paper - Papier filtre.
F : Glass cylinder - Cylindre de verre.
G : Silicone connecting tube-Tube de connexion.

\section{Selection procedure}

At the completion of each run, 25 flies were taken randomly from the attractant containing tube to initiate the next generation. Sexes were run separately, so that 50 individuals were transferred each generation.

Reverse selection was carried out by removing the flies from the control (distilled water) tube. The number of flies in this tube at the completion of each run was 
often less than 25, especially in the initial generations of selection. Fewer flies were then transferred to the next generation. When this number fell below 10 for either sex, an additional run was carried out to increase this number above 10 .

Control lines were maintained by transferring 25 males and 25 females to fresh bottles each generation. Flies were starved along with flies from the selection lines each generation, and a random sample of the survivors provided the founders of the next generation.

The responses of the lines to selection were examined with analyses of variance (ANOVAs) on data from each 5 generation interval. Replicate lines were treated as a random factor nested within the selection regime (increased/decreased attraction or no selection). The appropriate variance ratio for the selection regime effect is to test its mean square against the mean square for the nested line effect. The order in which lines were tested was randomized for each generation (block) and a block effect was separated from the error variance in the ANOVAs. This block effect tests for the tendency of the overall olfactory response to vary from one generation to the next, including any directional changes in the selected lines within the 5 generation interval.

\section{Longevity and electrophoresis}

Adult longevity was used to measure resource utilization according to a modification of the method of STARMER et al. (1977) as described by PARSONS et al. (1979). Flies (1-2 days old) were sexed without anaesthesia and 10 flies of each sex placed into vials to be exposed to vapours from solutions of chemicals. Genotypes at the TPI and GPDH loci were determined by starch gel electrophoresis according to the method of McKechNie et al. (1981). ADH genotypes were determined by «Cellogel » electrophoresis.

\section{Results}

\section{A. Dosage response curves}

The response curve for ethanol is plotted in fig. 2 a. Five replicate runs were a mass bred $D$. melanogaster population initiated from flies caught at the same site. Results are expressed as an attraction index (AI) defined by FuYAMA (1976) as $\mathbf{A I}=$ (number in attractant tube - number in control tube)/ total.

The response curve for ethanol is plotted in fig. 2 a. Five replicate runs were carried out at each concentration. Flies were attracted within the range 10 p. 100 0.1 p. 100 with maximum attraction at 1.0 p. 100. The response of both sexes is similar, although only females are attracted to 10 p. 100 ethanol. 
The response of flies to various concentrations of acetaldehyde are plotted in fig. $2 \mathrm{~b}$. A maximum response occurs at a concentration of $0.01 \mathrm{p}$. 100, with no attraction below 0.0001 p. 100 acetaldehyde.
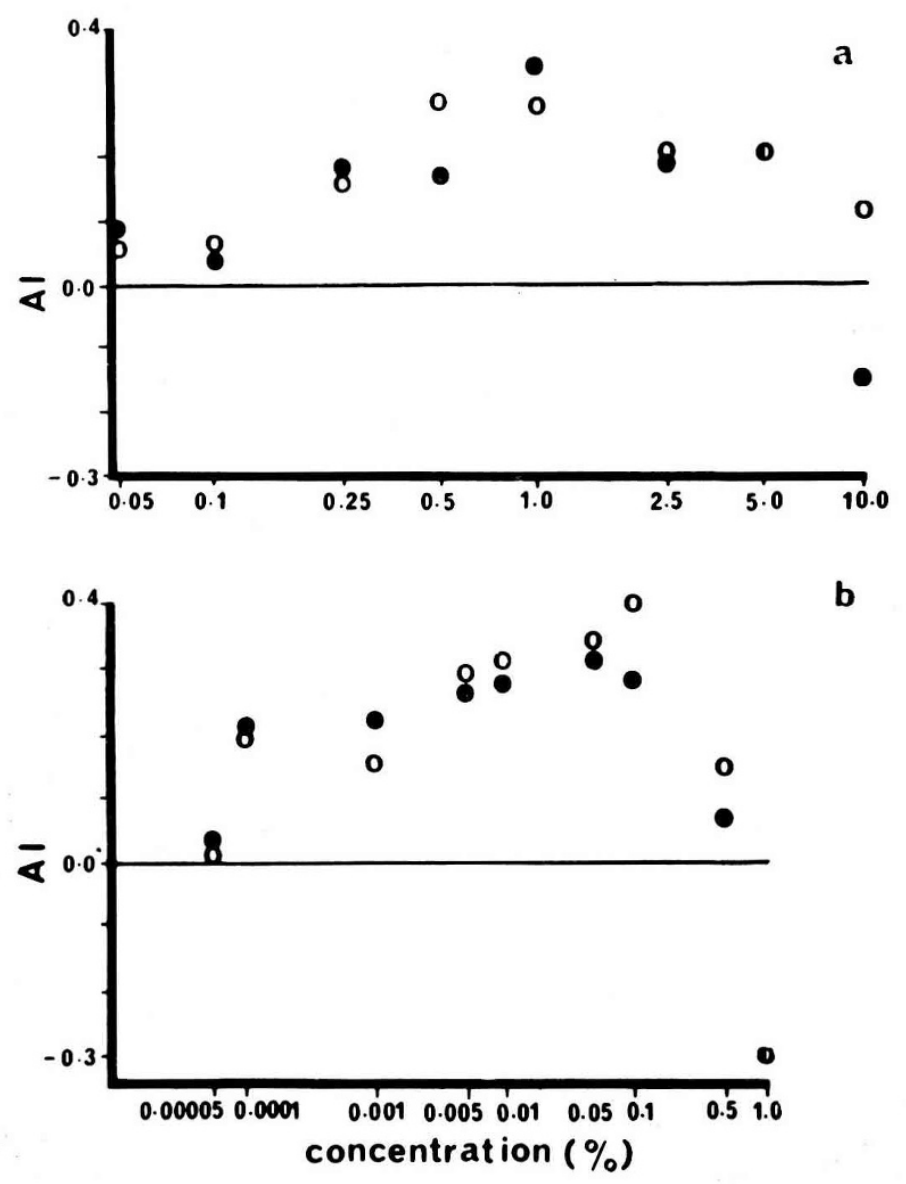

b

FrG. 2

Response of D. melanogaster to different concentrations of (a) ethanol and (b) acetaldehyde.

Réponse de D. melanogaster à diverses concentrations de (a) éthanol et (b) acétaldéhyde.

Each point is the mean of 5 experimental runs. Closed circle : males; open circles : females.

Chaque point est la moyenne de 5 expériences. Cercles noirs : mâles; cercles blancs : femelles. 


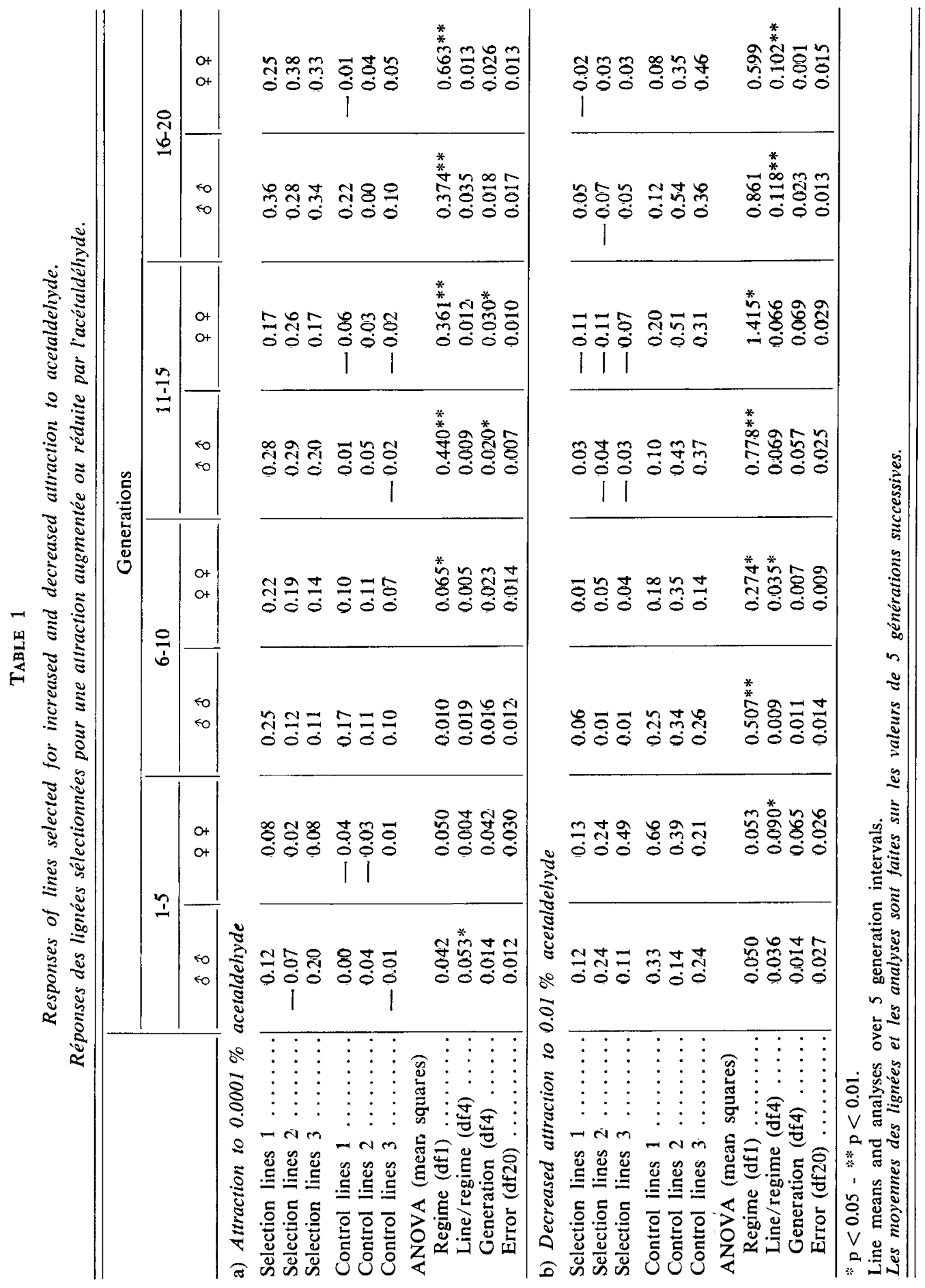




\section{B. Response to selection - acetaldehyde}

Flies were selected for increased attraction to 0.0001 p. 100 and 0.00001 p. 100 acetaldehyde. While the mass bred population was unresponsive to $0.00001 \mathrm{p} .100$ acetaldehyde, preliminary experiments with isofemale lines indicated that some extreme strains were attracted to this concentration. Hence a response to selection could occur, given the presence of such genetic variation in the selected population. Selection for decreased attraction was undertaken using 0.01 p. 100 acetaldehyde since the selection intensity was likely to be highest at the concentration evoking a maximum attraction response. Three selection lines for each concentration, as well as three control lines, were initiated with a random sample from the population cage when it was three generations removed from the field.

Selection for attraction to 0.00001 p. 100 was unsuccessful, and results are not presented. The response of the replicate lines at the other concentrations and the analyses over 5 generation intervals are summarised in table 1 . The results indicate a bidirectional response to selection for both the males and females. Lines selected for unresponsiveness differ from controls in the 6 to 10 generation interval. The selected lines show little response to 0.01 p. 100 acetaldehyde after 10 generations. There is significant variation among the replicate lines in the 16-20 generation interval for both sexes. This effect is due to one of the controls (line 1) which has a lower response to 0.01 p. 100 acetaldehyde than the other two control lines. Consequently, the selection regime effect is not significant in the 16-20 generation interval.

Selection for increased attraction to 0.0001 p. 100 acetaldehyde was successful for both sexes, with selection lines differing from the controls beyond generation 10 .

\section{Response to selection - ethanol}

Selection was carried out for increased attraction to 0.01 p. 100 ethanol and for decreased attraction to 1.0 p. 100 ethanol, these concentrations being used for the reasons given for acetaldehyde above.

Selection (tabl. 2) was again successful in both directions. Lines selected for decreased attraction differ from control lines beyond generation 5 . One of the controls (line 3) has a lower response to 0.01 p. 100 ethanol than the other two controls in the 16-20 generation interval, and this is responsible for the significant variation among lines in this interval.

Lines selected for increased attraction differ from the controls beyond generation 10. As in the case of acetaldehyde, there is no significant variation among the replicate lines.

\section{Correlated responses - other odorants}

Olfactory responses of the selected lines were investigated for a number of other odorants. Acetaldehyde and ethanol lines were tested for the chemicals (and concentrations) listed in tables 3 and 4 respectively. These chemicals are naturally occuring, and miscible with water at the concentrations used. Dosage response curves 


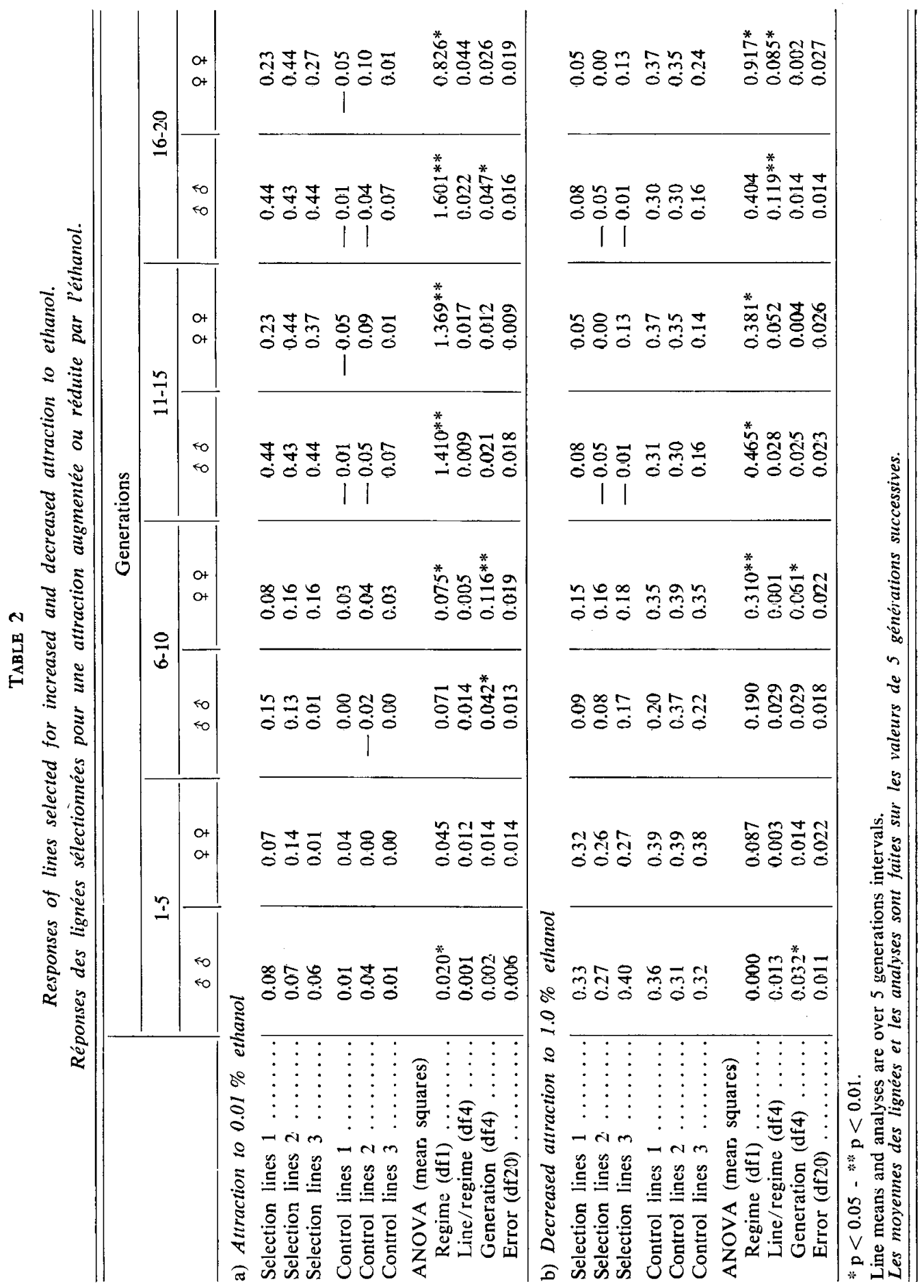


for the chemicals had previously been characterised for the mass bred population mentioned above (unpublished data). Mean AI values at the concentrations used (except benzaldehyde) were between 0.30 and 0.10 - within the response range encompassed by the selection and control lines. Benzaldehyde is unattractive to D. melanogaster, and flies are repelled at the 0.01 p. 100 concentration.

The response of only one sex was tested at each concentration. This enabled a larger number of odorants to be examined. Genetic variation for attraction to fermentation products is unlikely to be sex specific, since both sexes are attracted to food resources. This is confirmed by the published data. FuYAMA found that males and females from chromosome II lines responded similarly to esters and ketones (FuYAMA, 1978) and that sexes of geographic strains responded similarly to ethyl acetate, ethanol, lactic acid and n-butyraldehyde (FUYAMA, 1976). Additionally, preliminary experiments with isofemale lines had indicated that the response of males and females of these strains to various concentrations of acetaldehyde, ethanol and acetic acid was similar.

Results for acetaldehyde selected lines (tabl. 3) indicate that flies selected for decreased attraction are unresponsive to 0.001 p. 100 and 0.0001 p. 100 acetaldehyde. This suggests that the response to selection is not concentration specific. The two sets of lines do not differ in their response to any of the other chemicals tested. Hence variation between the lines is mostly odorant specific, indicating olfactory variation rather than selection for an apparatus related trait such as increased movement into the attractant containing tube.

The selection regime effect is not significant for benzaldehyde, the other aldehyde tested. However, mean AI values for the response by all the unresponsive lines are lower than for the attraction lines, and the significant variation among replicate lines may have obscured an effect of selection regime. This compares with the non significant line effects for the responses to acetaldehyde, and suggests that, if a correlated response is involved, the genetic system underlying the variation to these odorants is not identical.

Results for the ethanol selection lines are summarized in table 4. Odorants except benzaldehyde and n-butanol are attractive at the concentrations used. Butanol repels flies from the mass bred population at all concentrations eliciting a response.

The results indicate that selection lines differ in their response to both 0.1 p. 100 and 1.0 p. 100 ethanol, with means in the predicted direction. Few of the other chemicals show correlated responses, indicating odorant specific olfactory variation. Lines selected for decreased attraction to ethanol are unresponsive to n-propanol (1.0 p. 100). All lines selected for increased attraction are also more attracted to 0.1 p. 100 n-propanol than negatively selected lines, although the selection regime effect is not significant $[F(1,4)=6.3,0.10>p>0.05]$. Selection lines do not differ in their response to the other alcohol tested (n-butanol) although strain means are again in the predicted direction. This suggests that the correlated response is dependant upon the alcohol group. In both the case of n-butanol and n-propanol there is significant variation among replicate lines, which suggests that the genetic systems controlling these responses are not identical. Interestingly, one of the positively selected lines has become attracted to n-butanol, while the other two lines are no longer repelled, which compares with the repulsion of the mass bred population by all concentrations of this chemical eliciting a response. 


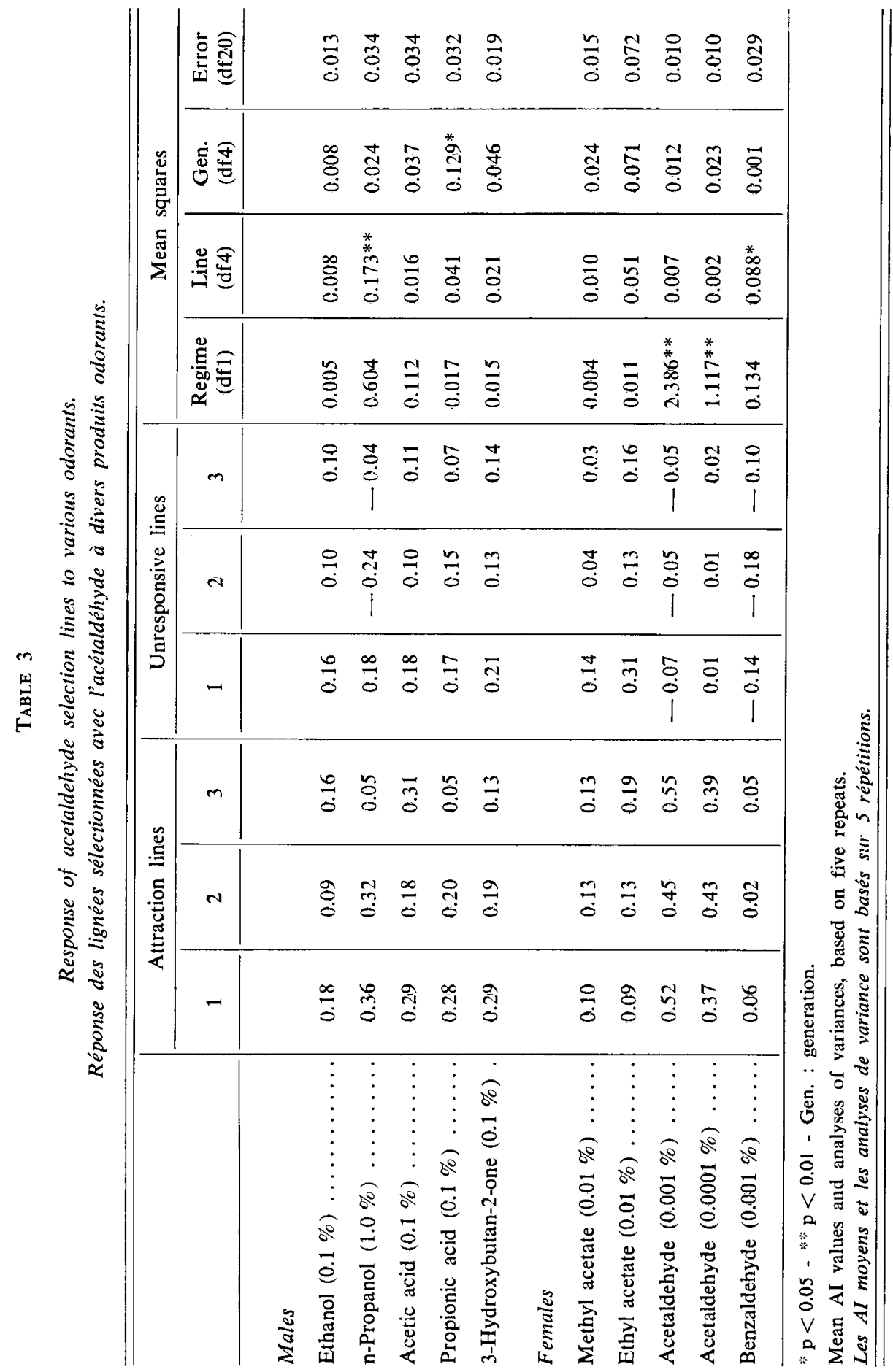




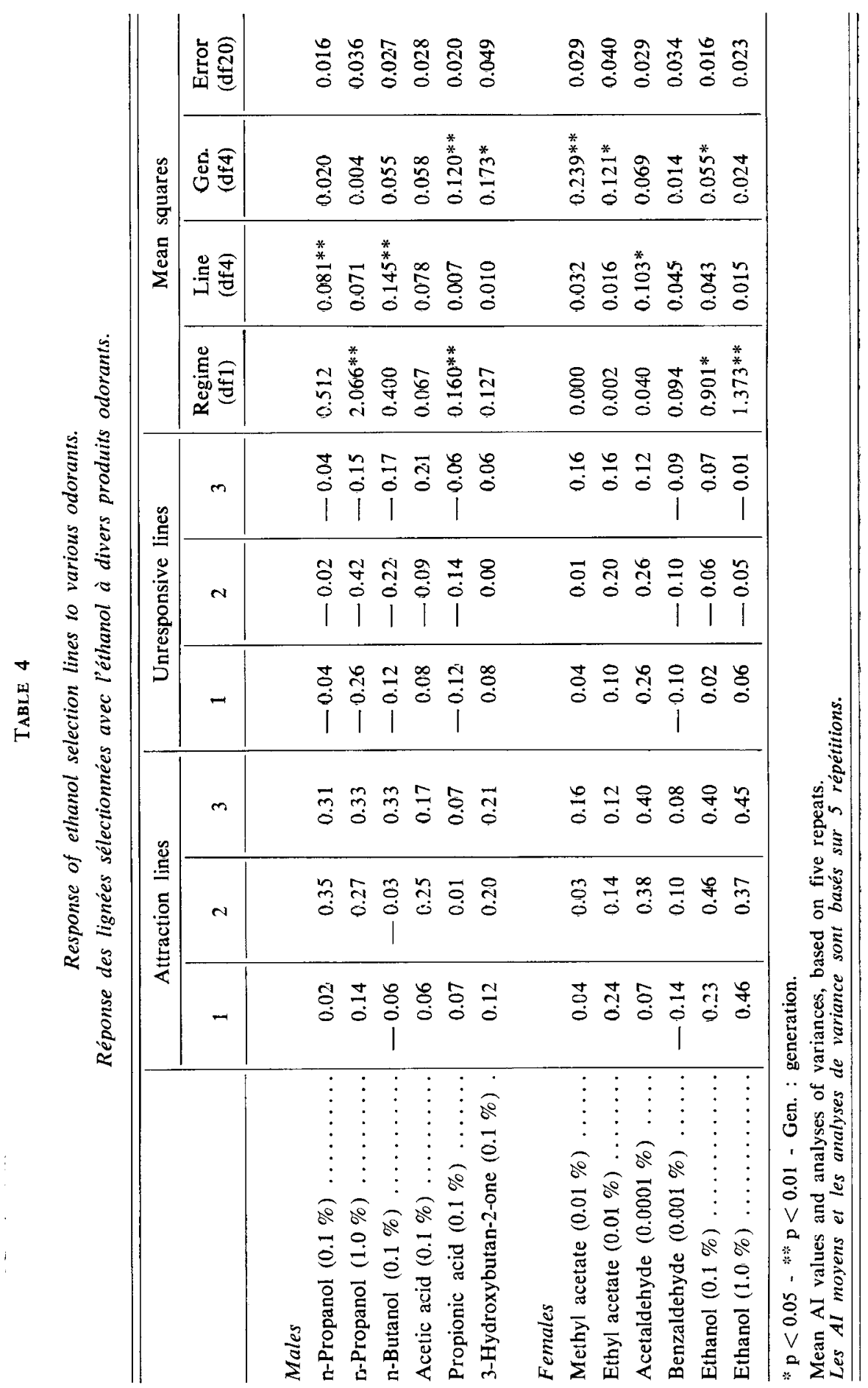




\section{E. Correlated responses - resource utilization}

The longevity method was used to examine whether selection for olfactory response to acetaldehyde and ethanol was accompanied by any change in the utilization of acetaldehyde, ethanol and acetic acid as resources. Results are expressed as LT50 values - the time taken for 50 p. 100 of the flies to die as calculated by linear interpolation. These values are then adjusted by division for the LT50 values obtained from distilled water controls, the trait of interest being the amount by which the longevity is increased by the chemical rather than longevity itself. Prior analysis of unpublished data from R. GuerRA (pers. comm.) suggested a linear relationship between LT50 and LT50 control values of approximately unit slope.

\section{TABLE 5}

Utilization of ethanol, acetaldehyde and acetic acid by the selected lines.

Utilisation de l'éthanol, de l'acétaldéhyde et de l'acide acétique par les lignées sélectionnées.

\begin{tabular}{l|l|l|l|l|l|l}
\hline \hline & \multicolumn{2}{|c|}{ Acetaldehyde } & \multicolumn{3}{|c|}{ Ethanol } & \multicolumn{2}{|c}{ Acetic acid } \\
\hline $0.1 \%$ & $1.0 \%$ & $2.5 \%$ & $9 \%$ & $12 \%$ & $2.5 \%$ & $9 \%$ \\
\hline
\end{tabular}

a) Acetaldehyde selection lines

\begin{tabular}{|c|c|c|c|c|c|c|c|}
\hline Attraction, lines $1 \ldots \ldots \ldots$ & 1.65 & 2.55 & 3.05 & 1.91 & 1.19 & 1.50 & 1.56 \\
\hline Attraction lines $2 \ldots \ldots \ldots$ & 1.84 & 1.25 & 2.52 & 1.98 & 0.87 & 1.41 & 1.11 \\
\hline Attraction lines $3 \ldots \ldots$ & 1.58 & 1.87 & 2.82 & 1.90 & 1.62 & 1.51 & 1.32 \\
\hline Unresponsive lines 1 & 1.81 & 2.82 & 2.66 & 2.40 & 1.51 & 1.47 & 1.08 \\
\hline Urresponsive lines 2 & 1.70 & 1.74 & 1.91 & 1.29 & 0.87 & 1.45 & 1.08 \\
\hline Unresponsive lines 3 & 1.96 & 2.50 & 2.91 & 1.76 & 1.33 & 1.51 & 1.47 \\
\hline \multicolumn{8}{|l|}{ ANOVA (mean squares) } \\
\hline Regime (df1) $\ldots \ldots \ldots$ & 0.136 & 1.561 & 0.636 & 0.097 & 0.001 & 0.047 & 0.120 \\
\hline Line/regime (df4) & 0.084 & 1.807 & $0.837^{*}$ & $0.769^{* *}$ & $0.617 *$ & 0.078 & 0.120 \\
\hline Error (df24) $\ldots$ & 0.084 & 0.698 & $0.2 ! 33$ & 0.131 & 0.200 & 0.121 & 0.328 \\
\hline
\end{tabular}

b) Ethanol selection lines

\begin{tabular}{|c|c|c|c|c|c|c|c|}
\hline Attraction lines .1 & 1.80 & 1.67 & 3.70 & 1.97 & 1.45 & 1.60 & 0.68 \\
\hline Attraction lines 2 & 1.61 & 2.13 & 3.34 & 1.89 & 1.31 & 1.32 & 1.18 \\
\hline Attraction lines 3 & 1.88 & 1.97 & 3.83 & 1.92 & 1.23 & 1.58 & 1.26 \\
\hline Unresponsive lines 1 & 1.97 & 1.95 & 3.14 & 1.74 & 1.17 & 1.52 & 1.04 \\
\hline Unresponsive lines 2 & 1.59 & 1.98 & 3.80 & 1.68 & 1.15 & 1.32 & 1.05 \\
\hline Unresponsive lines 3 & 1.98 & 2.95 & 3.32 & 1.42 & 1.08 & 1.19 & 0.61 \\
\hline \multicolumn{8}{|l|}{ ANOVA (mean sc } \\
\hline Regime (df1) $\ldots \ldots$ & 0.048 & 0.055 & 0.300 & $0.839^{*}$ & $0.286^{*}$ & 0.063 & 0.148 \\
\hline Line/regime (df4) & 0.171 & 0.168 & 0.471 & 0.079 & 0.036 & 0.086 & 0.406 \\
\hline Error (df24) $\ldots \ldots$ & 0.117 & 0.132 & 0.381 & 0.187 & 0.088 & 0.060 & 0.227 \\
\hline
\end{tabular}

$* \mathrm{p}<0.05-* * \mathrm{p}<0.01$.

Mean LT50/LT50 control scores and analyses of variance for 5 repeats.

Les valeurs correspondent au rapport : durée moyenne de survie des traités au temps de survie des témoins. Chaque traitement a été répété 5 fois. 
Table 5 presents the mean LT50/LT50 control values for the acetaldehyde selection lines and their analyses. There are no significant differences in the utilization of any of the chemicals by the two sets of lines.

The ethanol selected lines differed only in their utilization of 9 p. 100 and 12 p. 100 ethanol (tabl. 5). Means indicate that the positively selected lines utilize the ethanol to a greater extent.

\section{F. Correlated responses - electrophoretic markers}

Frequencies of the fast variant at the TPI, ADH, and GPDH loci before selection were $0.10(\mathrm{~N}=55), 0.61(\mathrm{~N}=64)$ and $0.73(\mathrm{~N}=55)$ respectively.

\section{TABLE 6}

Gene frequencies at three enzyme loci - Triose phosphate isomerase (TPI), a glycerophosphate dehydrogenase $(G P D H)$ and alcohol dehydrogenase ( $A D H)$ after 21 generations of selection.

Fréquences génétiques à trois locus enzymatiques après 21 générations de sélection.

\begin{tabular}{l|l|l|l|l|l}
\hline \hline GPDH-F & $\mathrm{N}$ & TPI-F & $\mathrm{N}$ & ADH-F & $\mathrm{N}$ \\
\hline
\end{tabular}

a) Acetaldehyde selection lines

Attraction lines $1 \ldots \ldots . .60 .77$

Attraction lines $2 \ldots \ldots \ldots .60 .93$

Attraction lines $3 \ldots \ldots \ldots .60 .64$

Unresponsive lines $1 \ldots \ldots . .60$

Unresponsive lines $2 . \ldots \ldots . .60$

Unresponsive lines $3 \ldots \ldots .60 .5$

Control lines $1 \ldots \ldots \ldots \ldots . .60 .69$

Control lines $2 \ldots \ldots \ldots \ldots .60 .68$

Control lines $3 \ldots \ldots \ldots \ldots$

\begin{tabular}{l|l}
39 & 0.08
\end{tabular}

\begin{tabular}{l|l|l|l}
0.08 & 37 & 1.00 & 33
\end{tabular}

\begin{tabular}{l|l|l|l|l}
36 & 0.13 & 36 & 1.00 & 33
\end{tabular}

36

42

0.09

0.98

33

53

0.14

0.13

1.00

33

78

0.14

1.00

33

72

45

44

0.12

0.20

0.98

33

1.00

33

1.00

$\begin{array}{lll}0.15 & 34\end{array}$

33

b) Ethanol selection lines

\begin{tabular}{lll|l|l|l|l|l|l} 
Attraction iines 1 & $\ldots \ldots$ & $\ldots .87$ & 42 & 0.21 & 40 & 0.95 & 33 \\
Attraction lines 2 & $\ldots \ldots$ & 0.83 & 45 & 0.14 & 39 & 1.00 & 33 \\
Attraction lines 3 & $\ldots \ldots$ & 0.81 & 36 & 0.10 & 44 & 0.98 & 33 \\
Unresponsive lines $1 \ldots \ldots \ldots$ & 0.88 & 41 & 0.14 & 38 & 1.00 & 33 \\
Unresponsive lines $2 \ldots \ldots \ldots$ & 0.81 & 43 & 0.11 & 39 & 0.85 & 33 \\
Unresponsive lines $3 \ldots \ldots \ldots$ & 1.00 & 46 & 0.21 & 35 & 1.00 & 33 \\
Control lines 1 & $\ldots \ldots \ldots$ & 0.84 & 36 & 0.17 & 64 & 1.00 & 33 \\
Control lines 2 & $\ldots \ldots \ldots \ldots$ & 0.81 & 42 & 0.12 & 33 & 0.77 & 33 \\
Control lines 3 & $\ldots \ldots \ldots$ & 1.00 & 42 & 0.18 & 50 & 0.95 & 33 \\
\hline
\end{tabular}

Gene frequencies after 21 generations of selection are given in table 6 . The frequencies of both ADH-F and GPDH-F alleles have increased in the ethanol selection lines. While there was a comparable increase of the ADH-F allele but not the GPDH-F allele in the acetaldehyde selection lines. 
Besides these overall trends, there is little association between selection regime and gene frequency changes. While some lines differ from one another, these are probably due to genetic drift, since there are no consistent changes in frequency for all the replicate lines.

\section{Discussion}

The results indicate odorant specific genetic variation in olfactory response, since increased or decreased attraction to one chemical was accompanied by correlated responses in only a few of the other chemicals tested. The genetic variation described by Fuyama $(1976,1978)$ for geographic strains and chromosome II lines was also odorant specific. Selection for ethanol did not result in a change in response to acetaldehyde (and vice-versa for acetaldehyde), suggesting that there are at least two independent genetic systems involved. The correlated responses of the other alcohols when ethanol was selected and possibly another aldehyde when acetaldehyde was selected suggests the importance of these chemical groups in determining the specificity of olfactory genetic variation. This was also observed by FuYAMA (1978) in the case of esters and ketones.

There is no correlation between olfactory responses to ethanol and the metabolically related acetic acid and acetaldehyde, suggesting that ethanol rather than one of its breakdown products elicits the olfactory responses. Parallel results were obtained by PARsons \& SPENCE (1981) for larval attraction by an ADH null strain. The null strain utilized ethanol as a resource at a minimal level, and was attracted to acetic acid but not ethanol.

The changes in allozyme frequencies during selection provide no evidence for the involvement of the allozyme loci in adult olfactory response. This contrasts with findings on larval attraction to ethanol by CAVENER (1979) and larval avoidance to ethanol by GeLFand \& McDonald (1981) with respect to the ADH locus.

The tendency of ADH-F to increase in frequency in all lines suggests that this allozyme may have been selected under the culture conditions of the ethanol lines, and this may obscure any role of the $\mathrm{ADH}$ locus in olfactory variation. An increase in the frequency of $\mathrm{ADH}-\mathrm{F}$ has been reported in other laboratory selection experiments, but only when the medium was supplemented with ethanol (GIBSON, 1970 ; VAN DELDEN et al., 1978). However, since a selection response was observed, the findings indicate that its effect on olfactory response variation is likely to be minor. The relationship between variation at the ADH locus with ethanol tolerance is also uncertain (GiBson et al., 1979 ; Ziolo \& PARSONS, 1982 ; DAvID et al., 1976).

The utilization of ethanol, acetic acid and acetaldehyde by the selected lines suggests little correlation between olfactory response and resource utilization. The one exception, the utilization of ethanol by ethanol selected lines, was only evident at two concentrations, despite 2.5 p. 100 ethanol being utilized as a resource to a greater extent than 9 p. 100 or 12 p. 100. This anomaly could be explained by the observation that the amount of genetic variation in adult longevity is concentration dependent, increasing at higher concentrations (PARSONS, 1983) when toxicity 
effects are likely to be more important. The difference in utilization parallels the results of Parsons \& Spence (1981) for the ADH strain mentioned previously.

The correlated responses between odorants found in this study and by FuYAma (1978) indicate genetic variation in olfactory response within populations specific to certain groups of odorants. This variation is potentially important in differential resource attraction under field conditions, since the odorants used are common in Drosophila breeding sites. One problem in extrapolating to field conditions is that olfactory behaviours elicited depend to some extent on the apparatuses used (KENNEDY, $1977 \mathrm{~b}$ ). It would be of interest to compare the performance of selected lines in other olfactometers, especially those permitting optomotor anemotaxis, the normal mechanism used by Drosophila in responding to distant food odors (KellogG et al., 1962 ; KeNNEDY, 1977 a).

Finally, studies on correlations among odorants in different populations could be used to examine changes in correlations during evolution. As recently noted by ARNOLD (1981), such studies on genetic correlations among behavioural traits in natural populations are rare. A number of chemicals could be evaluated as odorants and/or resources, to examine genetic correlations within and between these two sets of traits.

Received March 10, 1983.

Accepted June 13, 1983.

\section{Acknowledgements}

I thank Professor P.A. Parsons for his criticisms of this manuscript and K. Nielsen for carrying out the Cellogel electrophoresis. Two anonymous referees provided comments which improved the manuscript.

\section{References}

ARNOLD S.J., 1981. Behavioural variation in natural populations. I - Phenotypic, genetic and environmental correlations between chemoreceptive responses to prey in the garter snake, Thamnophis elegans. Evolution, 35, 489-509.

Barrow W.M., 1907. Reactions of the pomace fly to odorous substances. J. Exp. Zool., 4, 516-537.

CaVener D.R., 1979. Preference for ethanol in Drosophila melanogaster associated with the alcohol dehydrogenase polymorphism. Behav. Genet., 9, 359-365.

David J.R., Bouquet C., Arens M.F., Fouillet P., 1976. Biological role of alcohol dehydrogenase in the tolerance of Drosophila melanogaster to aliphatic alcohols : utilization of an ADH-null mutant. Biochem. Genet., 14, 989-997.

Fuyama Y., 1976. Behaviour genetics of olfactory response in Drosophila. I. Olfactometry and strain differences in Drosophila melanogaster. Behav. Genet., 6, 407-420.

Fuyama Y., 1978. Behaviour genetics of olfactory response in Drosophila. II. An odorantspecific variant in a natural population of Drosophila melanogaster. Behav. Genet., 8, 399-414.

Gibson J.B., 1970. Enzyme flexibility in Drosophila melanogaster. Nature, 227, 959-960. 
Gibson J.B., Lewis N., Adena M.A., Wilson S.R., 1979. Selection for ethanol tolerance in two populations of Drosophila melanogaster segregating alcohol dehydrogenase allozymes. Aust. J. Biol. Sci., 32, 387-399.

GELFAND L.J., MC Donald J.F., 1980. Relationship between ADH activity and behavioural response to environmental alcohol in Drosophila. Behav. Genet., 10, 237-249.

Hougouto N., Lietaert M.C., Libion-Mannaert M., Feytmans E., Elems A., 1982. Oviposition site preference and ADH activity in Drosophila melanogaster. Genetica, 58, 121-128.

Hutner S.H., Kaplan H.M., Enzmann E.V., 1937. Chemicals attracting. Drosophila. Am. Nat., 71, 575-581.

Kellogg F.E., Frizel D.E., Wright R.H., 1962. The olfactory guidance of insects. IV - Drosophila. Can. Entomol., 94, 884-888.

KENNEDY J.S., 1977 a. Olfactory responses to distant plant and other odor sources. In : SHOREY H.H., MCKELVEY J.J., Chemical control of insect behaviour : theory and application, 67-93. Wiley and Sons, New York.

KENNEDY J.S., 1977 b. Behaviourally discriminating assays of attractants and repellants. In : SHOREY H.H., MCKeLVEY J.J., Chemical control of insect behaviour : theory and application, 215-231. Wiley and Sons, New York.

McKechnie S.W., Kohane M., Phillips S.C., 1981. A search for interacting polymorphic enzyme loci in Drosophila melanogaster. In : GiBson J.B., OAKESHOTT J.G., Genetic structure of Drosophila populations, 121-138. Australian National University Press.

MCKechnie S.W., Morgan P., 1982. Alcohol dehydrogenase polymorphism of Drosophila melanogaster : aspects of alcohol and temperature variation in the larval environment. Aust. J. Biol. Sci., 35, 85-93.

McKenzie J.A., McKechnie S.W., 1979. A comparative study of resource utilization in natural populations of Drosophila melanogaster and D. simulans. Ecologia (Berl.), 40, 299-309.

McKenzie J.A., Parsons P.A., 1972. Alcohol tolerance : an ecological parameter in the relative success of Drosophila melanogaster and D. simulans. Ecologia (Berl.), 10, 373-388.

Moxon L.N., Holmes R.S., Parsons P.A., 1982. Comparative studies of aldehyde oxidase, alcohol dehydrogenase and aldehyde resource utilization among Australian Drosophila species. Comp. Biochem. Physiol., 71 B, 387-395.

Parsons P.A., 1983. The Evolutionary Biology of Colonizing Species. Cambridge University Press.

Parsons P.A., Spence G.E., 1981. Longevity, resource utilization and larval preferences in Drosophila : inter- and intraspecific variation. Aust. J. Zool., 29, 671-678.

Parsons P.A., Stanley S.M., Spence G.E., 1979. Environmental ethanol at low concentrations : longevity and development in the sibling species Drosophila melanogaster and D. simulans. Aust. J. Zool., 27, 747-754.

SACKTOR B., 1974. Biological oxidations and energetics in insect mitochondria. In : Rockstein M., The physiology of insecta, 271-353. Academic Press, New York.

Starmer W.T., Heed W.B., Rockwood-Sluss E.S., 1977. Extension of longevity in Drosophila mojavensis by environmental ethanol : differences between subraces. Proc. Natl. Acad. Sci. U.S.A., 74, 387-391.

Van Delden W., Boerema A.C., Kamping A., 1978. The alcohol dehydrogenase polymorphism in populations of Drosophila melanogaster. I - Selection in different environments. Genetics, 90, 161-191.

WEST A.S., 1961. Chemical attractants for adult Drosophila species. J. Econ. Entomol., 54, 677-681.

Ziolo L.K., Parsons P.A., 1982. Ethanol tolerance, alcohol-dehydrogenase activity and Adh allozymes in Drosophila melanogaster. Genetica, 57, 231-237. 